\section{MODELLING OF PARTIAL DISCHARGE ANALYSIS SYSTEM USING WAVELET TRANSFORM DENOISING TECHNIQUE IN LABVIEW ENVIRONMENT}

1 March 2019

eceived in revised form

16 July 2019

Accepted

18 July 2019

Published online 24 October 2019

A. Nazifah Abdullah*, S. H. K. Hamadi, M. Isa, B. Ismail, A. N. Nanyan, A. Z. Abdullah

High Voltage Transients \& Insulation Health (HVTrans) Group, Centre of Excellent Renewable Energy (CERE), School of Electrical System Engineering, Universiti Malaysia Perlis (UniMAP), Kampus Pauh Putra, 02600 Arau, Perlis, Malaysia
*Corresponding author nazifah@unimap.edu.my

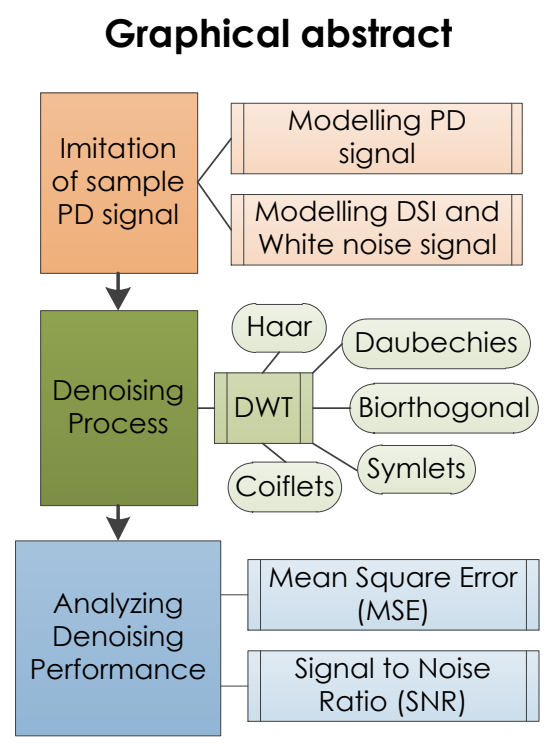

\begin{abstract}
Partial discharge (PD) measurement is an essential to detect and diagnose the existence of the PD. However, this measurement has faced noise disturbance in industrial environments. Thus, PD analysis system using discrete wavelet transform (DWT) denoising technique via Laboratory Virtual Instrument Engineering Workbench (LabVIEW) software is proposed to distinguish noise from the measured PD signal. In this work, the performance of denoising process is analyzed based on calculated mean square error (MSE) and signal to noise ratio (SNR). The result is manipulated based on Haar, Daubechies, Coiflets, Symlets and Biorthogonal type of mother wavelet with different decomposition levels. From the SNR results, all types of the mother wavelet are suitable to be used in denoising technique since the value of SNR is in large positive value. Therefore, further studies were conducted and found out that db14, coif3, sym5 and bior5.5 wavelets with least MSE value are considered good to be used in the denoising technique. However, bior5.5 wavelet is proposed as the most optimum mother wavelet due to consistency of producing minimum value of MSE and followed by dbl4.
\end{abstract}

Keywords: Partial discharge, denoising, wavelet, MSE, SNR

\begin{abstract}
Abstrak
Pengukuran discas separa (PD) adalah penting untuk mengesan dan mendiagnosis kewujudan PD. Walau bagaimanapun, pengukuran ini menghadapi gangguan hingar dalam persekitaran perindustrian. Oleh itu, sistem analisis PD yang menggunakan teknik nyah-hingar wavelet kecil diskret (DWT) melalui perisian LabVIEW dicadangkan untuk membezakan hingar dari isyarat PD yang diukur. Dalam kerja ini, prestasi proses penyah-hingar dianalisis berdasarkan pengiraan kesilapan purata persegi (MSE) dan nisbah gelombang kepada hingar (SNR). Hasilnya dimanipulasi berdasarkan jenis wavelet ibu Haar, Daubechies, Coiflets, Symlets dan Biorthogonal dengan tahap penguraian yang berbeza. Dari keputusan SNR, semua jenis wavelet ibu adalah sesuai sebagai kaedah nyah-hingar yang baik kerana nilai SNR adalah dalam nilai positif yang besar. Oleh itu, kajian lanjut telah dijalankan dan mendapati bahawa wavelet db14, coif3, sym5 dan bior5.5 dengan nilai MSE yang kecil dianggap sebagai kaedah nyah-hingar yang baik. Bagaimanapun, wavelet bior5.5 telah dicadangkan sebagai wavelet ibu yang paling optimum kerana konsistensi menghasilkan nilai minimum MSE dan diikuti oleh db14.
\end{abstract}

Kata kunci: Discas separa, nyah-hingar, wavelet, MSE, NSR

(C) 2019 Penerbit UTM Press. All rights reserved 


\subsection{INTRODUCTION}

Partial discharge (PD) has causes major problem such as insulation erode, losses, heat increased and immediate failure of the high voltage system due to aging and deterioration in insulation system. [1]. PD is also affected by environmental factors including discharge area, surface condition, temperature, and humidity [2]. Since PD usually occurs before complete breakdown, PD analysis system actually provides a warning to the system before damage and failure occurs. PD measurement and analysis system can help providing critical information on the quality of insulation and predicting future performance and reliability of electrical equipment [3], [4], [5].

However, PD measurement has faced problem in industrial environments such as noise in frequency measurement, signal attenuation in high frequency range and significant variation in PD activity over time [6], [7] Extracting the PD signal from noisy backgrounds is a major challenge for PD measurement. Removing noise from the measured data and preserve the pure structures of the PD signal is considered as a perfect denoising technique. The purpose of the denoising is to maintain the PD pulses and eliminating the noise and interferences [8], [9], [10].

Due to the frequency or spectral contents of the PD signals are constantly changing with respect to time, thus their energy spread throughout the band and still combined with the noise even it is extracted using a continuous and periodic base (sine and cosine) functions [11]. In addition, it is difficult to achieve high resolution and high precise time location via conventional numerical algorithms, such as Fast Fourier Transform (FFT). Therefore, even the Discrete Wavelet Transform (DWT) is a common technique that has been used widely in PD diagnostic and there are several types of denoising technique can be used, the DWT technique is still feasible and superior in rejecting various interference from the PD signal since other traditional techniques can only focus either on time or frequency domain resolution at a time [11], [12]. The nature of PD pulses is transient, irregular and nonperiodical in nature, while wavelet transform can analyze those pulse in both time-frequency domain simultaneously [13], [14].

In denoising signal process, three essential aspects that need to be considered, which are the decomposition level, the mother wavelet selection and the thresholding setting. Selection of types and number of order in mother wavelet will determine the accuracy of wavelet transform based on denoising result. The higher the order of wavelet, the smoother the wavelet [15], [16]. There are two categories of mother wavelets, such as orthogonal and biorthogonal. The examples of orthogonal are Haar, Daubechies, Coiflets and Symlets, meanwhile, for biorthogonal is BiorSplines [17]. Decomposition level is influenced by length of signal where higher level gives better denoising performance [15], [18], [19].

Therefore, in this research, the main contribution of this paper is to propose the most optimum DWT denoising technique based on different mother wavelets such as Haar, Daubechies, Coiflets, Symlets, and Biorthogonal for PD analysis system in LabVIEW environment. The performance of DWT denoising technique is evaluated based on Mean Square Error (MSE) and Signal to Noise ratio (SNR) analysis. This PD analysis system is aimed to be implemented in the actual PD diagnostic measurement by using file processing function in LabVIEW module. As for initial work, the actual pattern of PD signal is imitated first in this paper by modelling the PD and noise signals via LAbVIEW software.

\subsection{METHODOLOGY}

There are three main phases involved in this development of PD analysis system as shown in Figure 1, which are; data acquisition, data process and data analysis stages. Each phase is further divided into several stages which includes modelling of PD and noise signals, modelling of PD denoising system and analyzing the performance of denoising process based on MSE and SNR parameters as explained in the next subsection.

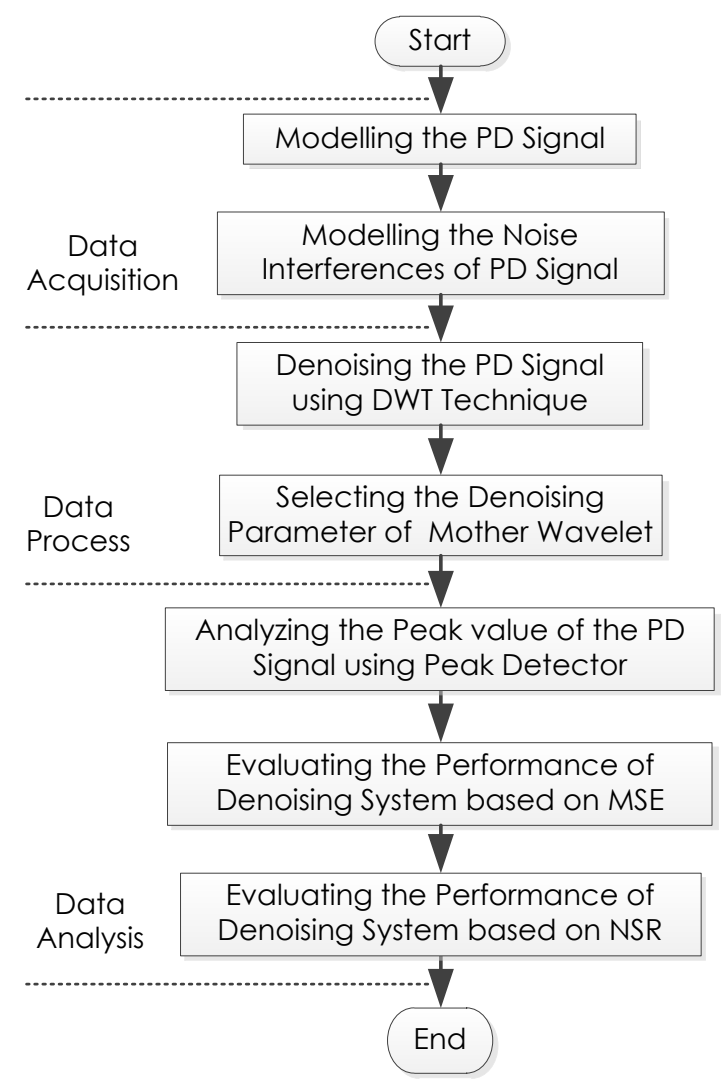

Figure 1 PD analysis system using wavelet transform denoising technique 


\subsection{Data Acquisition}

As in the first phase, data acquisition system (DAS) is the process of converting signal samples that measured in real physical circumstances into digital numeric values that can be manipulated by a computer [20]. In this phase, DAS is controlled by software programs which developed using various programming languages in LabVIEW software and converted the resulting PD signal samples into desired form as explained in next sub-section.

\subsubsection{Modelling of Partial Discharge Signal}

Since the shapes of PD pulses are depending on the type of detection circuit, the PD pulse in this simulation work is mathematically modelled by using LabVIEW software which is based on Equation 1 [16].

$$
i(t)=A\left[e^{-a_{1} t} \cos \left(w_{d} t-\varphi\right)-e^{-a_{2} t} \cos (\dot{\varphi})\right.
$$

Where, $A$ is the magnitude coefficient, $a_{1}=1 \times 10^{6} \mathrm{~s}$ 1, $a_{2}=1 \times 10^{7} \mathrm{~s}^{-1}, \varphi=\tan ^{-1}\left(w_{d} / a_{2}\right), w_{d}=2 \pi f_{d}$, and $f_{d}=$ $1 \mathrm{MHz}$.

PD pulse is transmitted through three core cable with 50mm² $\mathrm{Cu} / \mathrm{XLPE} / \mathrm{PVC}, 8.7$ / 15kV, and travelled at $156 \mathrm{~m} / \mu \mathrm{s}$ of propagation velocity. The simulated PD pulse also has shifted corresponding to the propagation velocity. The propagation velocity in the cable is defined in Equation 2 [21].

$$
v_{f}=\frac{v_{s}}{\sqrt{\varepsilon}}
$$

where $V_{f}$ is the propagation velocity, $V_{s}$ is propagation velocity in free space and $\varepsilon$ is effective relative permittivity of cable dielectric and semiconducting screen layers.

In order to model the PD signal in LabVIEW simulation, the time delay of the propagation pulse in the simulated PD signal must be computed. Since the characteristic of PD pulse is tend to propagate along the line, the propagation velocity of $156 \mathrm{~m} / \mu \mathrm{s}$ is used to determine the time delay as mentioned in [22]. Furthermore, the location of PD source in simulated study is assumed to be occurred at $2 \mathrm{~km}$ after front end of the cable as claimed by Montanari, 2016 in [23], [4]. Thus, by using both of these information, the time delay of the PD signal can be computed in the LabVIEW software by using Equation 3.

$$
T A=\frac{D_{A}}{v}
$$

Where TA is time delay of the propagation pulse in the simulated PD signal, $D_{A}$ is the distance of the PD source occurred from front end of the cable which is 2 $\mathrm{km}$, and $\mathrm{v}$ is propagation velocity of $156 \mathrm{~m} / \mu \mathrm{s}$.

The PD signal is then finally modeled based on the computed time delay using text-based script in the
MathScript Node which available in LabVIEW software. The MathScript Node is used to evaluate the scripts or programming that created in the MathScript Window as shown in Figure 2. The scripts are evaluated by producing text-based signal processing, analysis, and mathematical equation in graphical development environment of LabVIEW. The coding that written in the MathScript Node is based on Equation 1. Usually any inputs of the Mathscript are all arranged on the left side, while for outputs are on the right side so that easier to debug the coding of the MathScript. As example, parameters $A$ and $n$ that shown in Figure 2 are the inputs of the MathScripts, whereas parameter Delta is as the output.

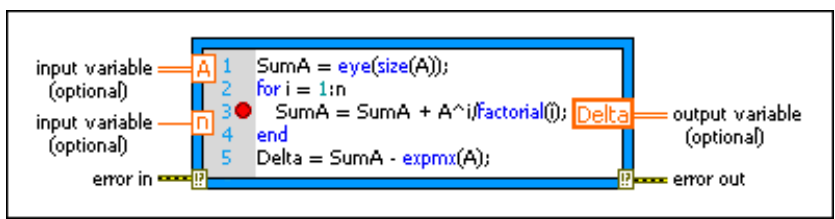

Figure 2 Example of MathScript Node to evaluate created scripts in the window

\subsubsection{Modelling Noise Interferences of the Partial Discharge}

In the PD measurement, the accuracy of the measurement is usually effected due to presence of a discrete spectral interferences (DSI) and also a white noise in the signal. DSI is a narrowband noise that resulted from the process of radio broadcasting during measurement [11]. Thus, the sinusoidal equation from Equation 4 is used to generate DSI signal by using formula waveform function in LabVIEW as shown in Figure 3. At this stage, various sinusoidal frequencies, which represented as $A_{i}^{\prime}$ are generated for each amplitude such as $600 \mathrm{kHz}, 800 \mathrm{kHz}, 1.5 \mathrm{MHz}$ and 5 $\mathrm{MHz}$.

$$
\operatorname{DSI}(t)=\sum_{i=1}^{N} A_{i}^{\prime} \sin 2 \pi f_{i} t
$$

where, $A_{1}=0.40 \mathrm{mV}, A_{2}=0.15 \mathrm{mV}, A_{3}=0.20 \mathrm{mV}, A_{4}$ $=0.35 \mathrm{mV}, f_{1}=600 \mathrm{kHz}, f_{2}=800 \mathrm{kHz}, f_{3}=1.5 \mathrm{MHz}$, and $f_{4}$ $=5 \mathrm{MHz}$.

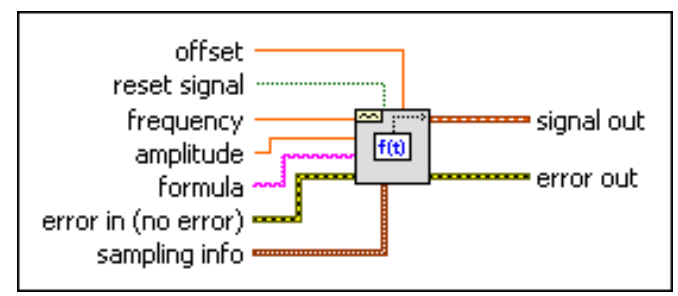

Figure 3 Waveform function to generate DSI signal 
Meanwhile waveform function as shown in Figure 4 is used to generate white noise interference. Then, both of PD and noise signals are combined in the LabVIEW using array function to imitate the real scenery of measured PD signal from measurement.

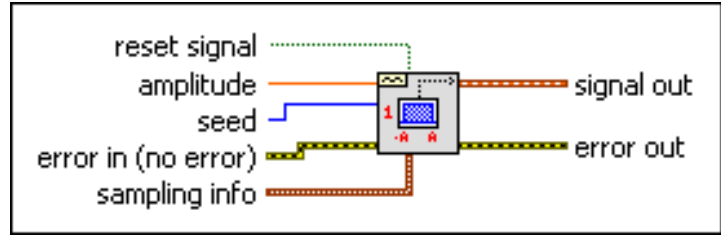

Figure 4 Uniform waveform function to generate White Noise Signal

\subsection{Data Process}

The second phase of this project development is the noise rejection process by using wavelet transform. With the capability to provide both time and frequency domains information, wavelet analysis is used to analyze a wide range of signal denoising in PD measurement signal. The core challenge in using wavelet analysis method are to identify the best optimum mother wavelet, decomposition level and the type of threshold for the signal to be denoised. This is because, different mother wavelet that applied on to the identical signal might produces different outcomes. Thus, different types of mother wavelet are first analyzed and the most optimum mother wavelet is proposed as part of the denoising process component in the PD analysis system developed.

\subsubsection{Denoising PD Signal using Discrete Wavelef Transform Technique}

An advanced signal processing toolkit for wavelet denoising analysis is expressed in LabVIEW function as shown in Figure 5. It is used to perform noise reduction for the imitated PD signal from measurement by using DWT.

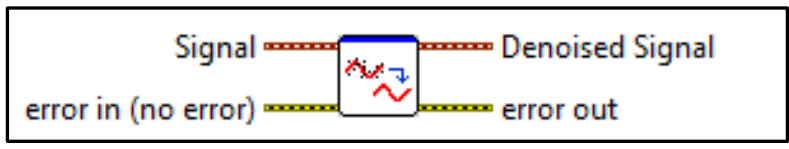

Figure 5 Wavelet function to perform noise reduction

The configuration of the transform settings and threshold settings of the wavelet denoising analysis are shown in Figure 6. It shows the sample of the simulated waveform result for the imitated original and denoised PD signals which is based on the input of the configuration. As discussed earlier, DWT is selected as the transform type in this configuration because of the advantage to analyze the signal in both time and frequency domains.
In addition, there are three important aspect in wavelet transform which are; the selections of decomposition level, type of mother wavelet, and threshold pattern. Level of decomposition also plays a major role in the performance of denoising PD signal. The decomposition level could be identified by two methods either a trial-error method or by computational formula. The maximum of the decomposition level, $\mathrm{L}$ is determined by Equation 5 [10].

$$
L=f i x(\log 2 n)
$$

where $n$ is the number of sampling and fix is function to round the value in the brackets to its nearest integer. Higher level of the decomposition will gives better denoising performance. In this simulation work, 10000 samples/second is used as the number of sampling. By using Equation 5 above, with the value of $n=10000$ samples/second, the calculated value of $L$ is equal to 4. Thus, maximum decomposition level selected for this work is level 4 [24].

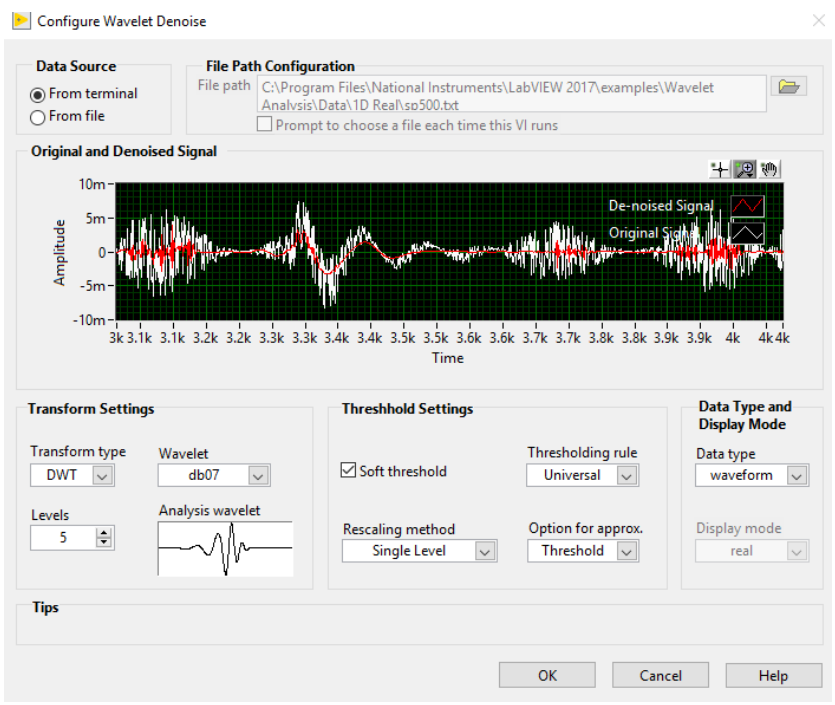

Figure 6 Configuration setting of Wavelet Denoise

\subsubsection{Selecting the Denoising Parameter of the Mother Wavelet}

Selection of accurate mother wavelet will help to determine the performance of the wavelet transform. Thus, five types of mother wavelet that been used in this denoising process are Haar, Daubechies, Biorthogonal, Coiflets and Symlets type which represented as Haar, db, Bior, Coif and Sym respectively. An information of function order in each types of mother wavelet is also essential since different order will gives different shape of denoising signal. The denoising signal becomes smoother by increasing the number of orders. These different types of mother wavelet are carried out with particular emphasis on 
the quantitative approaches in order to investigate the quality of denoised signal.

There is two type of the thresholding transformation which are soft and hard thresholds. The thresholding setting is significant in denoising process as hard thresholding is the modest method but soft thresholding is better in term of mathematical properties application. The soft thresholding was justified by [25] as best suited technique. Moreover, in thresholding setting also has an option between four type of threshold calculations rule, such as universal, SURE, hybrid or minimax. When the SNR of the noisy signal is low, the universal method is used to estimate the threshold. Lastly, minimax method which use the minimax principle to estimate the threshold also can be used as one the threshold option. Among four threshold calculation rules, this program used universal method as it is default in wavelet denoise function, [26], [27], [28]. In this work, each mother wavelet is tested with the same decomposition level at level 4 and the thresholding setting is as soft threshold with universal calculation rule.

\subsection{Data Analysis}

The effectiveness of the denoising result is depends on severity of resulted noise, mother wavelet chosen, maximum decomposition level taken, and thresholding rule adopted as previously explained. Thus, the third phase of this project development is to analyze the denoising signal performance based on calculated MSE and SNR parameters. The MSE and SNR are performance indices that have been used to quantify the denoising result and also to measure the effectiveness of the denoising method. The value of MSE and SNR are calculated to select the most optimum mother wavelet type in this denoising process. The objective of this optimization is to minimize the value of MSE and maximize the value of SNR simultaneously in order to propose optimum mother wavelet denoising method.

\subsubsection{Analyzing the Peak value of the PD Signal using Peak Detector}

In real PD measurement, the measured data needs to be processed to obtain PD characteristics such as peak value, apparent charge, phase position, repetition rate and $P D$ energy. The $P D$ detection method that uses a peak detector with thresholding technique can detect and count the peak value. Thresholding technique is aided in removing low voltage signal that consists the noise interference. Figure 7 shows the concept of peak detector and thresholding technique. The peak of PD signal can easily be detected by using this method.

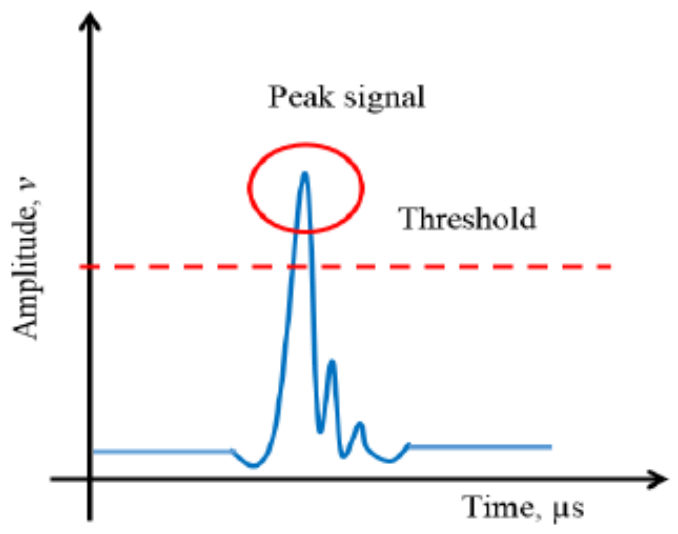

Figure 7 Concept of analyzing peak detection with thresholding technique [14]

Peak detection is one of the most important timedomain functions performed in signal monitoring. Peak detection is the process of finding the amplitudes of a peak that exceeds the threshold value. Threshold value acts as checkpoint and helps in monitoring the collected data. The peak signal that exceed the threshold value is indicated as a warning PD signal. In LabVIEW, Multiscale Peak Detector in Figure 8 is offered the ability to detect the peaks or valleys in a signal. The inputs for this function are input signal and threshold value, meanwhile the outputs are number of peaks, locations and amplitudes of peaks [29], [30].

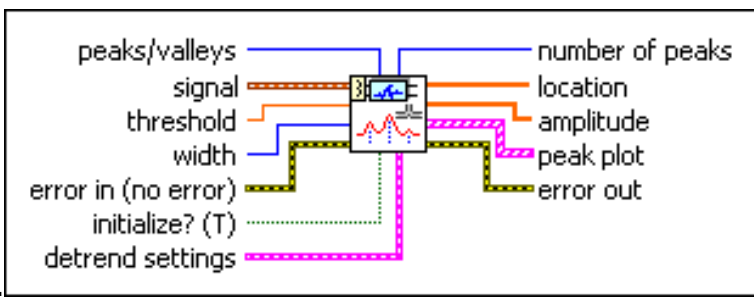

Figure 8 Multiscale peak detector function to detect the peak of a signal

\subsubsection{Analyzing the Performance of Denoising System based on Mean Square Error (MSE)}

MSE is used to evaluate the accuracy of denoising process as defined in Equation 6. The minimum value of MSE indicates better performance. Thus, a good mother wavelet is determined by the amount of MSE calculated. An algorithm is applied in the function to minimize the MSE [29], [30].

$$
M S E=\frac{1}{N} \sum_{i=1}^{N}(F(i)-R(i))^{2}
$$

Where $N$ is the length of PD signal, $F$ represents the reference $P D$ signal and $R$ is the denoised $P D$ signal.

In LabVIEW, MSE function is used as shown in Figure 9 to calculate the MSE value. The function will calculate the MSE of the input sequences $X$ and $Y$ 
values which is represented as an array of PD signal and denoised PD signal respectively. If the number of elements between $Y$ and $X$ values are different, the function will computes MSE based on the sequence that contains less elements and will returns a warning.

\begin{tabular}{|c|c|c|}
\hline$Y$ values & $\wedge \sigma \mu$ & \\
\hline X values & MSE & error \\
\hline
\end{tabular}

Figure 9 MSE function to calculate the value of MSE

\subsubsection{Analyzing the Performance of Denoising System based on Signal-to-Noise Ratio (SNR)}

SNR is a ratio of a signal power to a noise power that expressed in decibels (dB). The performance of denoising signal is evaluated by comparing the SNR between original PD signal, SNR and denoised PD signal, SNRdenby using Equations 7 and 8 respectively. Maximum of SNR will indicates as best performance of denoising result [29], [30].

$$
\operatorname{SNR}(d B)=10 \times \log \frac{\max (\text { signal })}{\max (\text { noise })}
$$

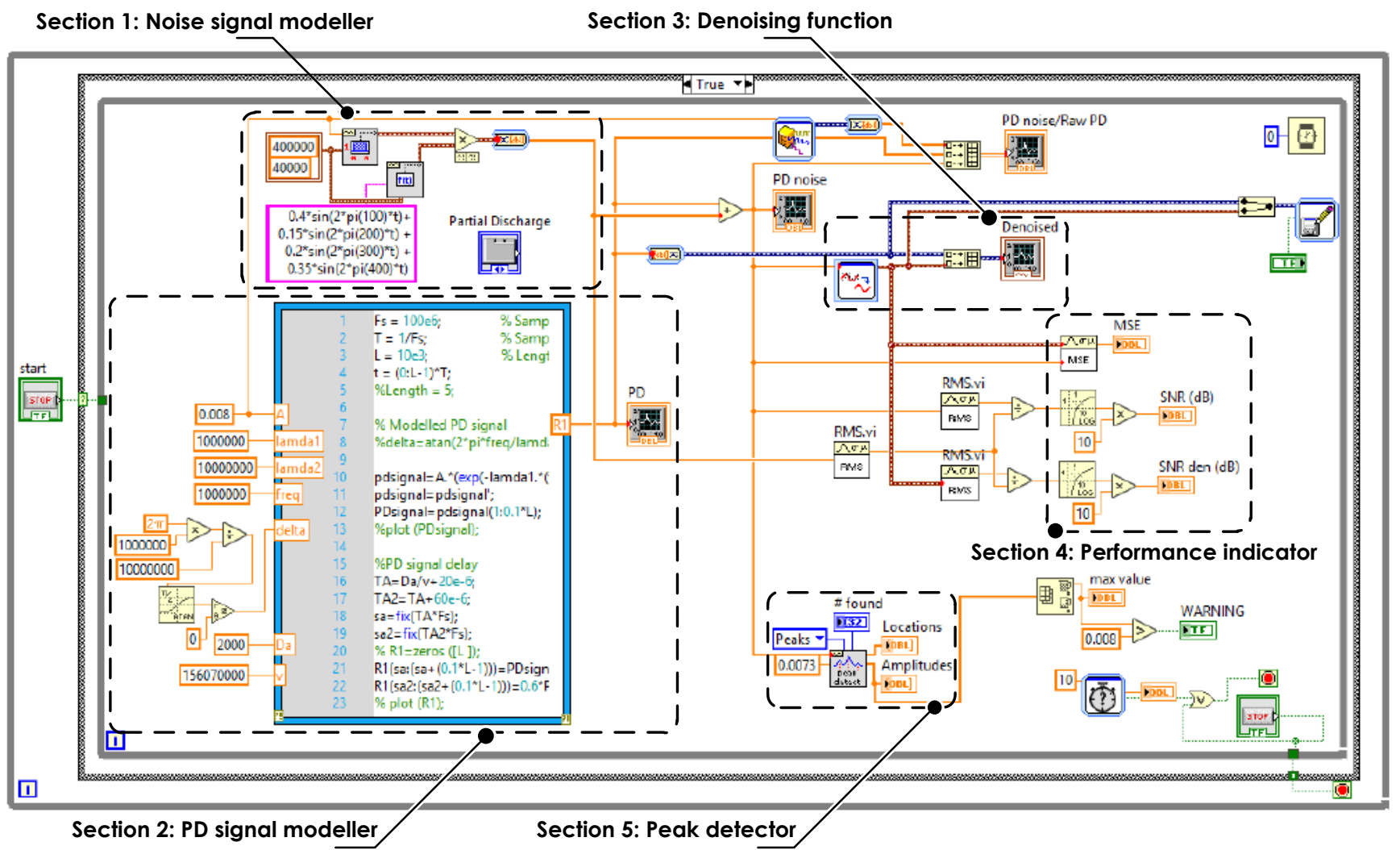

where, max(signal) and max(signal den) are the maximum value of PD signal that measured before and after the denoised process respectively. While max(noise) is represents the total noise signal for both situation each. Both equations are then designed in LabVIEW.

\subsection{The Proposed PD Analysis System}

Finally, the optimum mother wavelet and denoising technique is proposed based on optimization of the data analysis between minimum MNE and maximum SNR results. The proposed system is developed using LabVIEW software to display the PD signal. Figure 10 shows the block diagram panel with the connection of programming function of this simulation work. The block diagram panel contains the virtual instrument graphical source code that linked with the front panel. Indicator in the block diagram such as Boolean, numeric and graph indicator will be shown in the front panel. 


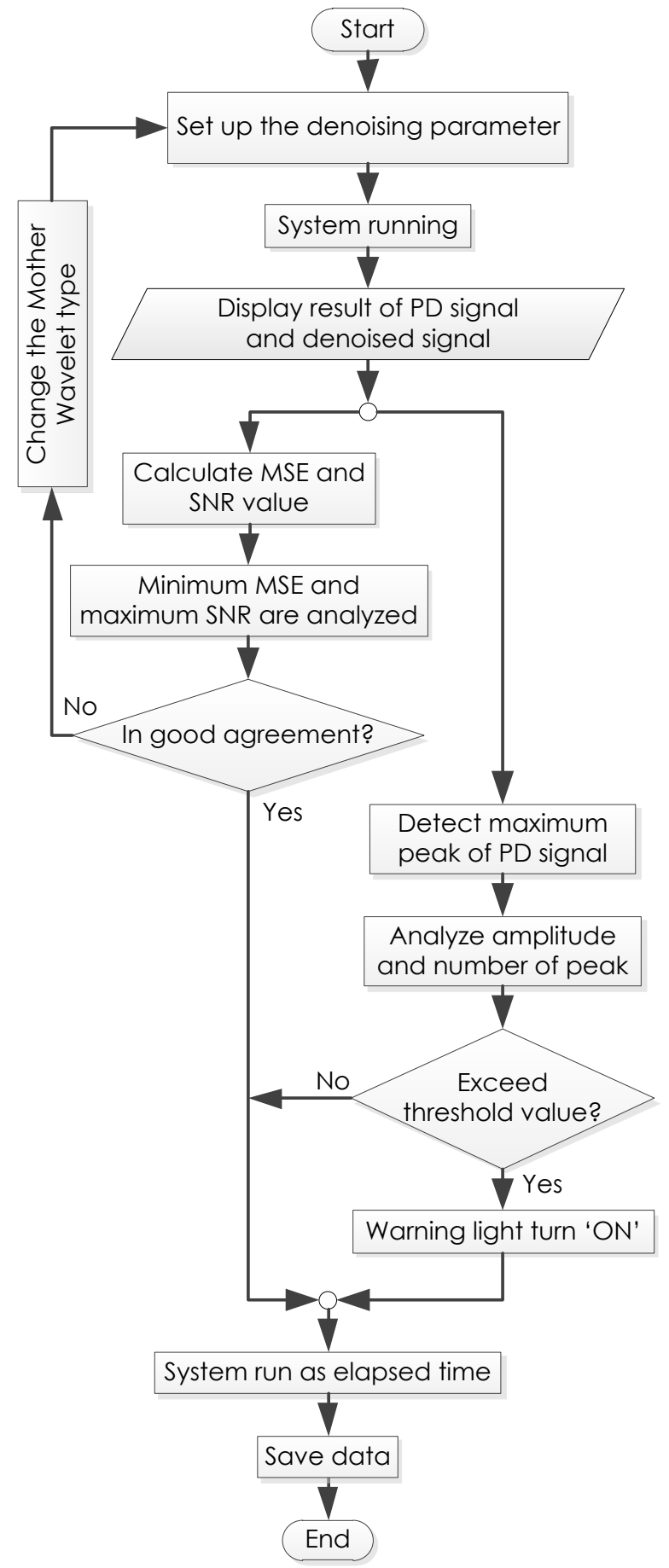

Figure 11 Flow chart of the front panel in the LabVIEW

At first, the denoising parameter such as type of mother wavelet, decomposition level and threshold setting are selected. Then, the front panel will display the PD signal and denoised PD signal. The maximum peak of the PD signal then will be analyzed and the warning will lights up if the maximum peak exceeds the threshold value. At the same time, the simulated MSE and SNR results are shown in numeric indicator on the front panel. Finally, the optimum mother wavelet and denoising technique is proposed based on data analysis between minimum MNE and maximum SNR results.

As can be seen from the block diagram in Figure 10, this PD analysis system is divided into five major sections which are modelling of noise signal, modelling of PD signal, denoising of PD signal, evaluating performance indices and evaluating peak detection. In this simulation, DSI and white noise are modelled using LabVIEW function as shown in Section 1 from the block diagram. Then, PD signal is modelled and coded using equation in MathScript function in Section 2. Next, as showed in Section 3, the wavelet analysis packet is used in denoising process by using wavelet transform technique. Both MSE and SNR values then are simulated in the block diagram panel in Section 4 to evaluate the performance indices of denoised signal. Last but not least, the peak detector from Section 5 of the block diagram will count and find the peak amplitude of the PD signal that exceeds the threshold value which explained earlier that threshold value is simulated based on soft threshold and using universal threshold rule in LabVIEW.

\subsection{RESULTS AND DISCUSSION}

The imitated PD signal with noise interference and the denoised PD signal using DWT technique are presented in this section. The denoised signal from this proposed PD analysis system is verified by the calculation of MSE and SNR value. The value of SNR is compared between the values before denoised and after denoised. The results of MSE and SNR values for various types of mother wavelet are also discussed. Minimum value of MSE and maximum value of SNR will indicate the most optimum mother wavelet type for the PD denoising technique.

\subsection{Results of Imitated PD Signal with Noise Interference}

Figure 12 shows the imitated PD signal that added with both White Noise and DSI in a voltage against sampling number. The signal is simulated in LabVIEW software by using up to 10000 sampling number and $1 \mathrm{MHz}$ samples per seconds. Thus, the time can be determined by multiplying the number of samples with $10 \mu \mathrm{s}$. As labelled in the figure, the red line graph shows the actual PD signal, while the black graph line shows the combination of PD signal and both noises. For clearer view, the waveform is enlarged within range of 3000 to 4000 number of samples. The result shows that PD could occur in short duration of time which is between $0.032 \mu \mathrm{s}$ and $0.037 \mu \mathrm{s}$, then propagate after several microseconds. 


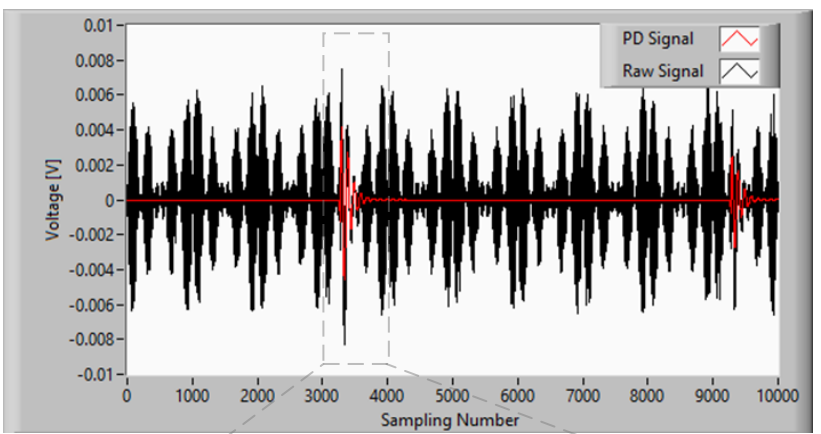

(a)

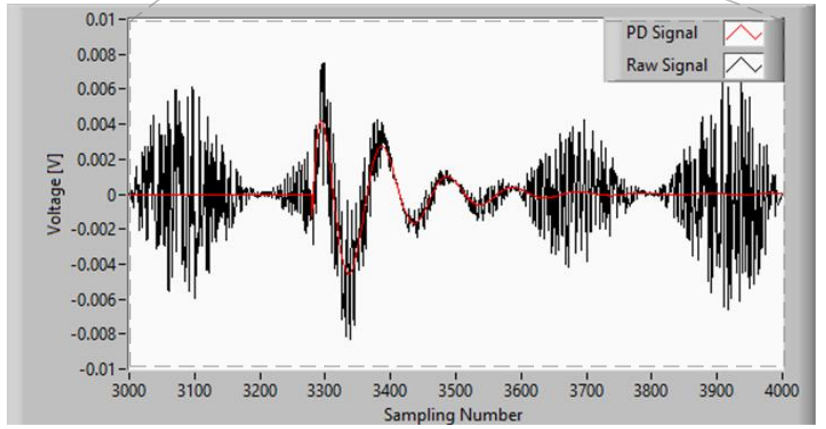

(b)

Figure 12 (a) Initial PD signal with both White Noise and DSI in voltage against sampling number. (b) Enlarged of the PD signal between 3000 to 4000 sampling number

\subsection{Results of the Performance of Denoising System based on MSE and SNR Analysis}

Table 1 shows result of performance index of PD denoising technique for various types of mother wavelet from the LabView simulation results. MSE and SNR are calculated to analyze the optimum types of mother wavelet for PD denoising technique. The objective of this analysis is to acquire minimum value of MSE and maximum value of SNR simultaneously in order to propose an optimum denoising method.

SNR value is calculated where higher SNR value will signify better performance of denoising process. As can be seen in Table 1, the SNR value of the PD signal is also calculated for the both situasion, before and after denoising process. More positive value of SNR indicates a larger power of the signal as compared to the noise and vice versa. From the SNR results, all types and number of orders of the mother wavelets are acceptable as good denoising method. Thus, a further performance of denoising system study based on MSE is carried out.

The minimum value of MSE value is considered as good denoising process. Haar mother wavelet commonly generates square wave shaped due to its simplest wavelet. Thus, denoising signal using Haarl wavelet for PD signal is inappropriate.

In Daubechies wavelet, the MSE value decreases from db2 until db14. There are small differences of MSE value in between db9 until dbl4. In Coiflets wavelet, the MSE value decrease from coifl until coif3, but increases back until coif5. Coifl has higher MSE value in Coiflets family. Coif3 has the smallest value among the Coiflets wavelet, which is $0.2838 \times 10^{-5}$. The pattern in Symlets wavelet is similar with Coiflets wavelet. The MSE decreases from sym2 until sym5 and increase at sym6. Sym7 and sym8 have small value than sym6 but not the least MSE in Symlets family. MSE value in Biorthogonal wavelet fluctuated as shown in Table 1. Bior1.3 and bior 1.5 have small MSE value and then the value is increased to $0.3279 \times 10^{-5}$ at bior2.2. MSE value started to decrease from bior2.2. MSE value in bior3.3 until bior3.9 is high while bior4.4 and bior6.8 is low. The least MSE value in Biorthogonal wavelet is $0.2762 \times 10^{-5}$ at bior5.5.

Table 1 Results of performance index for each mother wavelet

\begin{tabular}{|c|c|c|c|c|}
\hline Mother Wavelet & $\begin{array}{l}\text { No. of } \\
\text { Order }\end{array}$ & MSE $\left(\times 10^{-5}\right)$ & SNR (dB) & $S N R_{d e n}(d B)$ \\
\hline Haar (haar) & 1 & 0.2819 & 0.0934 & 5.9357 \\
\hline \multirow{13}{*}{ Daubechies (db) } & 2 & 0.3071 & 0.0857 & 6.4979 \\
\hline & 3 & 0.2977 & 0.0883 & 6.267 \\
\hline & 4 & 0.3038 & 0.0857 & 6.1575 \\
\hline & 5 & 0.2833 & 0.0825 & 6.0757 \\
\hline & 6 & 0.2902 & 0.0918 & 5.8792 \\
\hline & 7 & 0.2958 & 0.0830 & 6.0433 \\
\hline & 8 & 0.2875 & 0.0857 & 5.8713 \\
\hline & 9 & 0.2842 & 0.0811 & 5.7837 \\
\hline & 10 & 0.2867 & 0.0998 & 5.7631 \\
\hline & 11 & 0.2905 & 0.0931 & 5.8456 \\
\hline & 12 & 0.2872 & 0.0890 & 5.6950 \\
\hline & 13 & 0.2867 & 0.0877 & 5.8834 \\
\hline & 14 & 0.2823 & 0.0887 & 5.4941 \\
\hline \multirow{5}{*}{ Coiflets (coif) } & 1 & 0.3028 & 0.0863 & 6.5799 \\
\hline & 2 & 0.2889 & 0.0866 & 6.0108 \\
\hline & 3 & 0.2838 & 0.0907 & 5.8190 \\
\hline & 4 & 0.2948 & 0.0872 & 6.2756 \\
\hline & 5 & 0.2924 & 0.0952 & 5.9551 \\
\hline \multirow{7}{*}{ Symlets (sym) } & 2 & 0.3024 & 0.0930 & 6.2106 \\
\hline & 3 & 0.3035 & 0.1118 & 5.9200 \\
\hline & 4 & 0.2973 & 0.0908 & 6.4569 \\
\hline & 5 & 0.2884 & 0.0896 & 5.8851 \\
\hline & 6 & 0.3081 & 0.0822 & 6.3927 \\
\hline & 7 & 0.2944 & 0.0922 & 5.9953 \\
\hline & 8 & 0.2988 & 0.0837 & 5.9802 \\
\hline \multirow{14}{*}{$\begin{array}{l}\text { Biorthogonal } \\
\text { (bior) }\end{array}$} & 1.3 & 0.2893 & 0.1105 & 5.6987 \\
\hline & 1.5 & 0.2912 & 0.0784 & 5.7347 \\
\hline & 2.2 & 0.3279 & 0.0834 & 7.2723 \\
\hline & 2.4 & 0.3172 & 0.1019 & 6.7064 \\
\hline & 2.6 & 0.3264 & 0.0676 & 7.2616 \\
\hline & 2.8 & 0.3205 & 0.0802 & 7.0862 \\
\hline & 3.1 & 0.3356 & 0.0726 & 4.95342 \\
\hline & 3.3 & 0.3219 & 0.0792 & 6.4229 \\
\hline & 3.5 & 0.3265 & 0.0834 & 6.7200 \\
\hline & 3.7 & 0.3239 & 0.0721 & 6.9832 \\
\hline & 3.9 & 0.3227 & 0.1111 & 6.3988 \\
\hline & 4.4 & 0.3013 & 0.0861 & 6.0062 \\
\hline & 5.5 & 0.2762 & 0.0887 & 5.3790 \\
\hline & 6.8 & 0.3062 & 0.0877 & 6.4638 \\
\hline
\end{tabular}


Based on the result, four mother wavelets with small MSE value are chosen as acceptable good denoising processed, which are db14, coif3, sym5 and bior5.5. However, bior5.5 and $\mathrm{db} 14$ had consistently give minimum MSE value. Therefore, bior5.5 is suggested as the most optimum mother wavelet type and followed by $\mathrm{db} 14$.

\subsection{Results of Denoised PD Signal using DWT Technique}

The imitated PD signal is denoised to discriminate unwanted noise interferences. The denoised signal are analyzed using six different types of mother wavelet and each results presented by focusing between 3000 to 4000 number of samples. Figures 13(a)-(f) show the initial imitated PD and denoised signals based on haar 1, db7, db 14, coif3, sym5 and bior5.5 respectively.

Haarl is the simplest possible wavelet. The result shows the square shaped signal with sharp signal

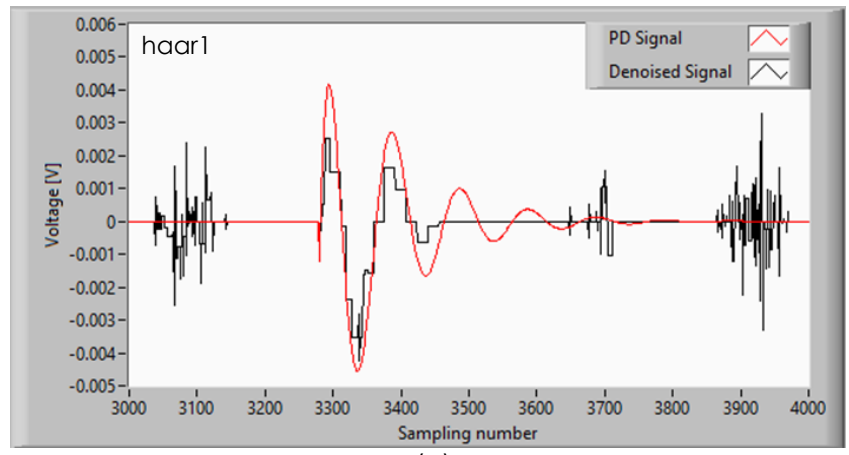

(a)

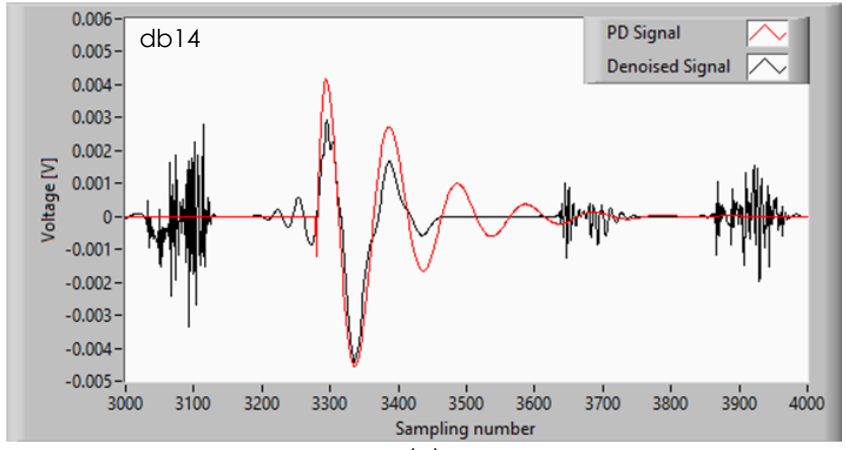

(c)

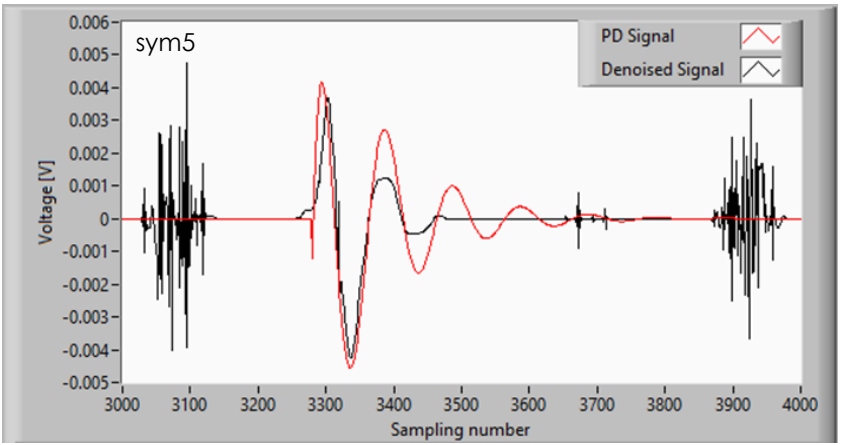

(e) edge. Haar wavelet is also known as first order of Daubechies wavelet, dbl. Daubechies wavelet family is the most popular for feature analysis due to compact support abilities. As the number of order in Daubechies wavelet increases, the signal becomes smoother. The denoising process that applied $\mathrm{db} 7$ showed a better performance with smoother signal compared to db 14. Coiflets was originally derived from the Daubechies wavelet. The wavelet is near symmetric and had been used in many applications. Symlets wavelet are Daubechies least symmetric wavelets and are very compactly supported. Biorthogonal wavelet exhibits the properties of linearity which is advantageous for image and signal reconstruction. Biorthogonal system provides an additional degree of freedom than the orthogonal wavelets.

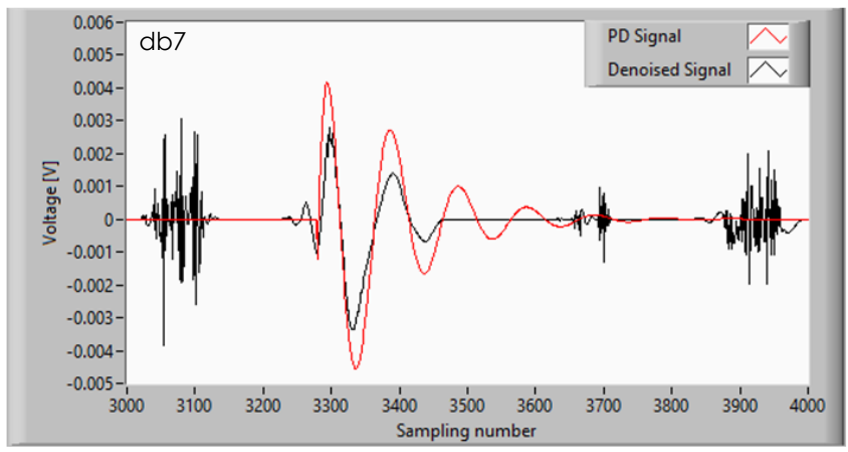

(b)

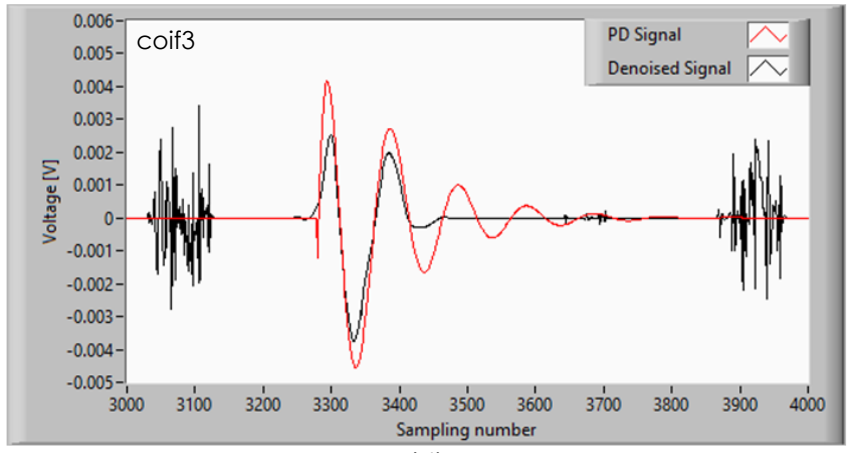

(d)

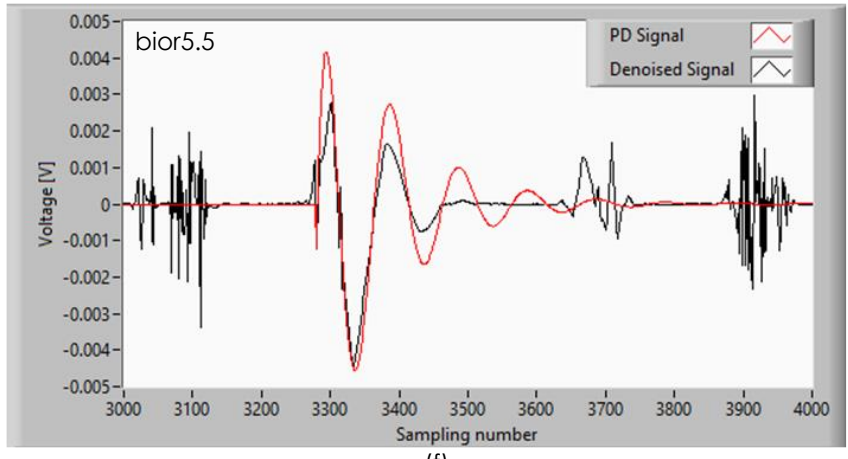
(f)

Figure 13 Results of the initial imitated PD signal and the denoised signal using mother wavelet of (a) Haarl, (b) db7, (c) db 14, (d) coif3, (e) sym5 and (f) bior5.5 
In Section 3.2, bior5.5 had generated minimum MSE values and therefore be chosen as a good mother wavelet for PD denoising technique. This is followed by $\mathrm{db}$ 14. However, if refer to Figure 13 (c), the denoised signal by $\mathrm{db} 14$ does not identical with the actual PD signal, same also with Figure 13 (f) by bior5.5. As discussed earlier, the main focus of this paper is to propose the best mother wavelet type for PD denoising technique based on lowest MSE parameter within six families of mother wavelet that up to 41 number of orders. Thus, the identical or uniformity between patterns of denoised PD signal and actual PD signal from Figure 13 are not the main consideration in this paper.

\subsubsection{Analysis Results of Decomposition Level using Various Mother Wavelet}

Decomposition level is one of the important aspects that need to be considered in denoising the PD signal using DWT. As discussed in Equation 4, decomposition level is influenced by length of signal. The previous six mother wavelets are used to test four different decomposition levels by analyzing their MSE value as shown in Figure 14. From the result, all MSE value for each type of mother wavelet is decreased when the decomposition level is larger from level one up to level four. Thus, it shows level four has better denoising performance due to its minimum value of MSE.

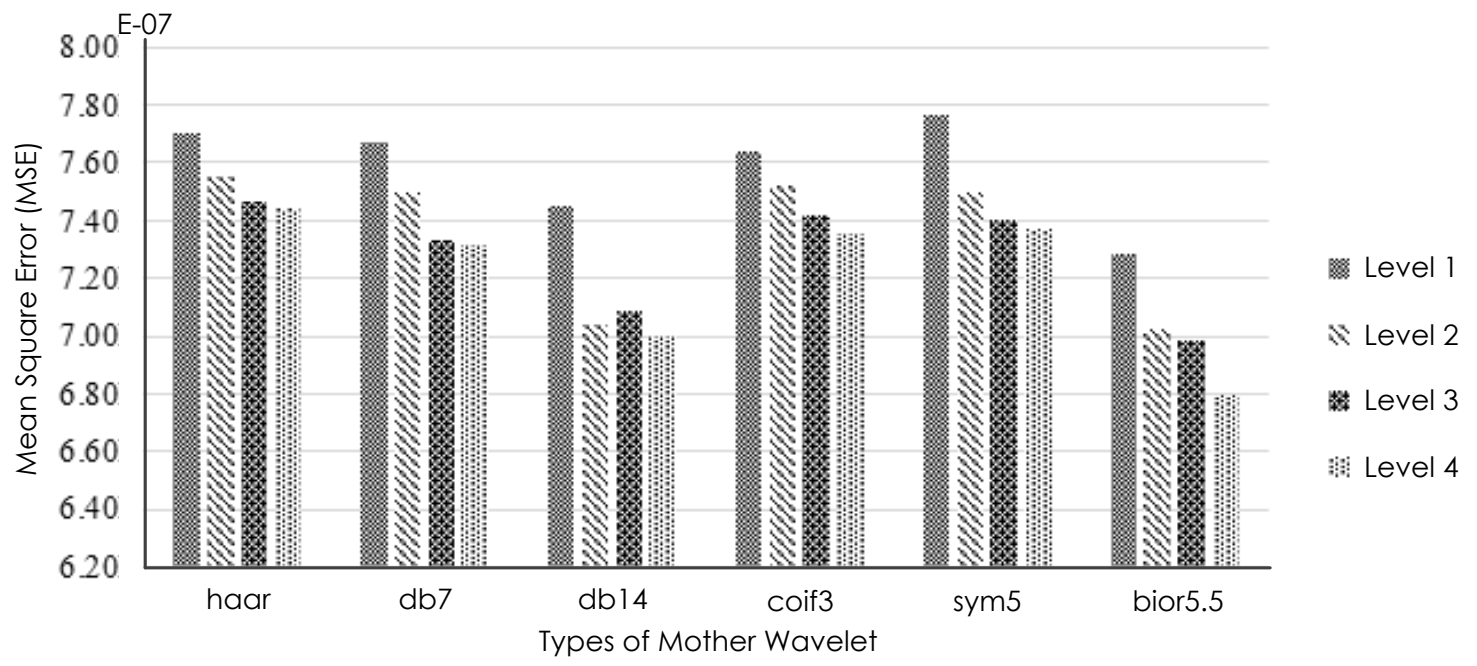

Figure 14 Bar chart result of the MSE value of decomposition level for each mother wavelet

\subsection{CONCLUSION}

In this work, PD analysis system was developed using Laboratory Virtual Instrument Engineering Workbench (LabVIEW) software. PD and noise signals was also modelled using the mathematical equation and function in LabVIEW software to imitate real PD signal. This analysis system had included the denoising process using DWT technique to distinguish the unpleasant noise. SNR and MSE are calculated for each five types of mother wavelet to assess the most optimum mother wavelet between Haar, Daubechies, Coiflets, Symlets and Biorthogonal wavelet on the performance of denoising process.

It was found that Bior5.5 wavelet had the lowest MSE value, followed by $\mathrm{db} 14$. Thus the most optimum for PD denoising application is Bior5.5 and $\mathrm{db} 14$. For the effect of db7, coif3 and sym5 on the denoising process, all three factors also showed significant influence on the denoising performance. However, denoising technique using haarl wavelet for PD signal is inappropriate.

\section{Acknowledgement}

This research is fully supported by SLAB/SLAl program. The authors fully acknowledged Ministry of Education Malaysia and Universiti Malaysia Perlis for the approved fund which makes this important research viable and effective.

\section{References}

[1] J. A. Ardila-Rey, J. M. Martínez-Tarifa, G. Robles, and M. Rojas-Moreno. 2013. Partial Discharge and Noise Separation by Means of Spectral-power Clustering Techniques. IEEE Trans. Dielectr. Electr. Insul. 20(4): 14361443.

[2] A. Z. Abdullah, H. Hamid, and M. Isa. 2018. Real On-site Partial Discharge Measurement Technique in Medium Voltage Power Cable. 2018 IEEE 7th Int. Conf. Power Energy Where. 1: 405-408.

[3] D. Salathe. 2015. New Methods for Offline PD Diagnosis on MV Cable Systems. 30th Power System ConferenceTehran, Iran. November: 374-379.

[4] M. N. K. H. Rohani et al. 2016. Geometrical Shapes Impact on the Performance of ABS-based Coreless Inductive Sensors for PD Measurement in HV Power Cables. IEEE 
Sens. J. 16(17): 6625-6632.

[5] B. Han, Q. Xue, X. Liu, and K. Wang. 2017. Multi-objective Optimization Design of a High-speed PM Machine Supported by Magnetic Bearings. Mech. Syst. Signal Process. 92: 349-363.

[6] I. Blokhintsev, B. J. Cassidy, and C. L. Patterson. 2009. Advantage of On-line Partial Discharge Continuous Monitoring of Medium Voltage Substation. 2009 IEEE Electr. Insul. Conf. Montr. QC, Canada. June: 153-158.

[7] M. N. K. H. Rohani, M. Isa, M. Syahril, C. C. Yii, A. S. Rosmi, and B. Ismail. 2018. Sigma-delta ADC Topology Implementation Based on Partial Discharge Detection using Rogowski Coil Sensor. J. Phys. Conf. Ser. 1019(1): 1-8.

[8] A. Mukhtaruddin, M. Isa, M. R. Adzman, S. I. S. Hasan, M. N. K. H. Rohani, and C. C. Yii. 2016. Techniques on Partial Discharge Detection and Location Determination in Power Transformer. 2016 3rd Int. Conf. Electron. Des. ICED 2016. 537-542.

[9] C. C. Yii, M. N. K. H. Rohani, M. Isa, S. I. S. Hassan, B. Ismail, and N. Hussin. 2015 Multi-end Partial Discharge Location Algorithm based on Trimmed Mean Data Filtering Technique for MV Underground Cable. 2015 IEEE Student Conference on Research and Development (SCOReD) IV. 345-350.

[10] S. H. K. Hamadi et al. 2017. Modelling of Partial Discharge Signal and Noise Interference using LabVIEW. IEEE 15th Student Conference on Research and Development (SCOReD). 451-455.

[11] M. Isa, N. I. Elkalashy, M. Lehtonen, G. M. Hashmi, and M. S. Elmusrati. 2012. Multi-end Correlation-based PD Location Technique for Medium Voltage Coveredconductor Lines. IEEE Trans. Dielectr. Electr. Insul. 19(3): 936-946.

[12] X. Zhou, C. Zhou, and B. G. Stewart. 2006. Comparisons of Discrete Wavelet Transform, Wavelet Packet Transform and Stationary Wavelet Transform in Denoising PD Measurement Data. Electr. Insul. 2006. Conf. Rec. 2006 IEEE Int. Symp. 237-240.

[13] G. M. Hashmi, M. Lehtonen, and M. Nordman. 2010. Calibration of On-line Partial Discharge Measuring System using Rogowski Coil in Covered-conductor Overhead Distribution Networks. IET Sci. Meas. Technol. 5(1): 5-13.

[14] M. N. K. H. Rohani et al. 2016. Effect of Unshielded and Shielded Rogowski Coil Sensor Performance for Partial Discharge Measurement. 2015 IEEE Student Conf. Res. Dev. SCOReD 2015.21-25.

[15] L. M. Ishak et al. 2017. Partial Discharge Location Algorithm Based on Cross-Correlation Technique for Unsynchronized Measurement. 2017 IEEE 15th Student Conference on Research and Development (SCOReD). 388-391.

[16] C. C. Yii, M. N. K. H. Rohani, M. Isa, and S. I. S. Hassan. 2017. Multi-end PD Location Algorithm using Segmented Correlation and Trimmed Mean Data Filtering Techniques for MV Underground Cable. IEEE Trans. Dielectr. Electr. Insul. 24(1): 92-98.

[17] C. F. F. De, A. T. D. Carvalho, M. R. Petraglia, and A. C. S. Lima. 2013. An Improved Scale Dependent Wavelet Selection for Data Denoising of Partial Discharge Measurement. Proceedings of IEEE International
Conference on Solid Dielectrics, ICSD. 100-104

[18] N. A. Yusoff, M. Isa, H. Hamid, M. R. Adzman, M. Nur, and K. Hafizi. 2016. Denoising Technique for Partial Discharge Signal: A Comparison Performance between Artificial Neural Network, Fast Fourier Transform and Discrete Wavelet Transform. 2016 IEEE International Conference on Power and Energy (PECon). 311-316.

[19] W. Li. 2009. Research on Extraction of Partial Discharge Signals based on Wavelet Analysis. Proceedings - 2009 International Conference on Electronic Computer Technology, ICECT 2009. 545-548.

[20] J. Du, W. Li, and J. Guo. 2018. Design of LabVIEW based General Data Acquisition System. Proc. 2017 IEEE 2nd Inf. Technol. Networking, Electron. Autom. Control Conf. ITNEC 2017. 2018-Janua: 1235-1239.

[21] E. Ouatah, S. Megherfi, K. Haroun, and Y. Zebboudj. 2013. Characteristics of Partial Discharge Pulses Propagation in Shielded Power Cable. Electric Power Systems Research. 38-44.

[22] A. A. Khan, N. Malik, A. Al-Arainy, and S. Alghuweinem. 2013. Investigation of Attenuation Characteristics of PD Pulse during Propagation in XLPE Cable. IEEE Power and Energy Society General Meeting. 4-8.

[23] G. C. Montanari. 2016. Partial Discharge Detection in Medium Voltage and High Voltage Cables: Maximum Distance for Detection, Length of Cable, and Some Answers. 32(5): 41-46.

[24] S. H. K. Hamadi et al. 2017. Evaluation of Denoising Performance Indices for Noisy Partial Discharge Signal Based on DWT Technique. 2017 IEEE 15th Student Conference on Research and Development (SCOReD), 1: 392-397.

[25] S. Madhu, H. B. Bhavani, and S. Sumathi. 2015. Performance Analysis of Thresholding Techniques for Denoising of Simulated Partial Discharge Signals Corrupted by Gaussian White Noise. Proc. 2015 IEEE Int. Conf. Power Adv. Control Eng. ICPACE 2015. 399-404.

[26] H. D. O. Mota, L. C. D. Da Rocha, T. C. D. M. Salles, and F. H. Vasconcelos. 2011. Partial Discharge Signal Denoising with Spatially Adaptive Wavelet Thresholding and Support Vector Machines. Electr. Power Syst. Res. 81 (2): 644-659.

[27] Ö. Altay and Ö. Kalenderli. 2010. Noise Reduction on Partial Discharge Data with Wavelet Analysis and Appropriate Thresholding. 2010 International Conference on High Voltage Engineering and Application, ICHVE 2010.

[28] H. Zhang, T. R. Blackburn, B. T. Phung, and D. Sen. 2007. A Novel Wavelet Transform Technique for On-line Partial Discharge Measurements Part 1: WT De-Noising Algorithm. IEEE Trans. Dielectr. Electr. Insul. 14(1): 3-14.

[29] R. Hussein, A. H. El-Hag, and K. B. Shaban. 2016. Energy Conservation-based Thresholding for Effective Wavelet Denoising Of Partial Discharge Signals. IET Sci. Meas. Technol. 10(7): 813-822.

[30] R. Hussein, K. B. Shaban, and A. H. El-Hag. 2015. Histogrambased Thresholding in Discrete Wavelet Transform for Partial Discharge Signal Denoising. 2015 International Conference on Communications, Signal Processing, and Their Applications, ICCSPA 2015. 1-5. 